Chapman University

Chapman University Digital Commons

Pharmacy Faculty Articles and Research

School of Pharmacy

2013

\title{
Non-Motile Primary Cilia as Fluid Shear Stress Mechanosensors
}

Surya M. Nauli

Chapman University, nauli@chapman.edu

Xingjian Jin

University of Toledo

Wissam A. AbouAlaiwi

University of Toledo

Wassim El-Jouni

Harvard University

Xuefeng Su

Harvard University

See next page for additional authors

Follow this and additional works at: http://digitalcommons.chapman.edu/pharmacy_articles

Part of the Cells Commons

\section{Recommended Citation}

Nauli SM, Jin X, AbouAlaiwi WA, El-Jouni W, Su X, Zhou J. Non-motile primary cilia as fluid shear stress mechanosensors. Methods Enzymol. 2013;525:1-20. doi: 10.1016/B978-0-12-397944-5.00001-8

This Article is brought to you for free and open access by the School of Pharmacy at Chapman University Digital Commons. It has been accepted for inclusion in Pharmacy Faculty Articles and Research by an authorized administrator of Chapman University Digital Commons. For more information, 


\section{Non-Motile Primary Cilia as Fluid Shear Stress Mechanosensors}

\section{Comments}

NOTICE: this is the author's version of a work that was accepted for publication in Methods in Enzymology. Changes resulting from the publishing process, such as peer review, editing, corrections, structural formatting, and other quality control mechanisms may not be reflected in this document. Changes may have been made to this work since it was submitted for publication. A definitive version was subsequently published in Methods in Enzymology, volume 525, in 2013. DOI: 10.1016/B978-0-12-397944-5.00001-8

\section{Copyright}

Elsevier

\section{Authors}

Surya M. Nauli, Xingjian Jin, Wissam A. AbouAlaiwi, Wassim El-Jouni, Xuefeng Su, and Jing Zhou 


\title{
Non-Motile Primary Cilia as Fluid Shear Stress Mechanosensors
}

\author{
Surya M. Nauli ${ }^{*}, 1$, Xingjian Jin ${ }^{*}$, Wissam A. AbouAlaiwi ${ }^{\star}$, Wassim El-Jouni ${ }^{\dagger}$, Xuefeng Su $^{\dagger}$, \\ and Jing Zhou ${ }^{\dagger, 1}$ \\ "Department of Pharmacology, The University of Toledo, Toledo, Ohio, USA \\ ${ }^{\dagger}$ Renal Division, Department of Medicine, Brigham and Women's Hospital, Harvard Medical \\ School, Boston, Massachusetts, USA
}

\begin{abstract}
Primary cilia are sensory organelles that transmit extracellular signals into intracellular biochemical responses. Structural and functional defects in primary cilia are associated with a group of human diseases, known as ciliopathies, with phenotypes ranging from cystic kidney and obesity to blindness and mental retardation. Primary cilia mediate mechano- and chemosensation in many cell types. The mechanosensory function of the primary cilia requires the atypical Gprotein-coupled receptor polycystin- 1 and the calcium-permeable nonselective cation channel polycystin-2. Mechanical stimulations such as fluid-shear stress of the primary cilia initiate intracellular calcium rise, nitric oxide release, and protein modifications. In this review, we describe a set of protocols for cell culture to promote ciliation, mechanical stimulations of the primary cilia, and measurements of calcium rise and nitric oxide release induced by fluid shear stress.
\end{abstract}

\section{INTRODUCTION}

Nonmotile primary cilia are sensory organelles projected from the apical membrane of most cells (Fig. 1.1A). Although primary cilia have been observed for over a century, their functions have only been revealed in the past decade. Among many other functions, such as the control of cell size (Boehlke et al., 2010) and the cell cycle (AbouAlaiwi, Ratnam, Booth, Shah, \& Nauli, 2011; Zhou, 2009), the mechanosensory function of the primary cilia is probably one of the most studied (Nauli, Haymour, AbouAlaiwi, Lo, \& Nauli, 2011; Resnick, 2011).

As a mechanosensory organelle, a primary cilium can sense body fluid movement in all visceral organs (Abdul-Majeed \& Nauli, 2011c). These include urine in the renal nephron (Nauli et al., 2006; Xu et al., 2007, 2009), nodal flow in Hensen's node (McGrath, Somlo, Makova, Tian, \& Brueckner, 2003), bile in the hepaticbiliary system (Masyuk et al., 2006), digestive fluid in the pancreatic duct (Cano, Murcia, Pazour, \& Hebrok, 2004; Cano, Sekine, $\&$ Hebrok, 2006), dentin in dental pulp (Magloire, Couble, Romeas, \& Bleicher, 2004; Thivichon-Prince et al., 2009), lacunocanalicular fluid in bone and cartilage (Hou,

(c) 2013 Elsevier Inc. All rights reserved.

${ }^{1}$ Corresponding authors: surya.nauli@utoledo.edu; zhou@ rics.bwh.harvard.edu. 
Kolpakova-Hart, Fukai, Wu, \& Olsen, 2009; Lu et al., 2001; Xiao et al., 2006), blood invasculature (Abou Alaiwi et al., 2009; Nauli et al., 2008), and cerebral spinal fluid in the nervous system (Fuchs \& Schwark, 2004). To exert their sensory functions, cilia require functional sensory proteins. Cells without these proteins or with structural defective cilia are unable to sense fluid-shear stress, but their sensitivity toward other mechanical or pharmacological stimuli remains intact (Nauli et al., 2003, 2008). The functional machineries found on the cilia include mechanosensory receptor-like protein polycystin-1, mechanosensory calcium-permeable cation channel polycystin-2 (Nauli et al., 2003, 2008), and other interacting proteins, such as fibrocystin (Nauli et al., 2003, 2008), and G-proteincoupled receptors (Nauli et al., 2011). As a sensory organelle, the ciliary membrane contains many receptors and signaling molecules regulating several cellular pathways such as the platelet-derived growth factor receptor-a (Schneider et al., 2010, 2009), receptors of the hedgehog signaling pathway patched and smoothened (Ingham et al., 2011), Wnt receptor frizzled (Luyten et al., 2010), Notch (Ezratty et al., 2011), matrix receptor integrins (McGlashan et al., 2006; Praetorius et al., 2004), and several other G-protein-coupled receptors, for example, the somatostatin receptor-3 (Handel et al., 1999), serotonin receptor 6, melanin-concentrating hormone receptor 1 (Berbari, Johnson, Lewis, Ask with, \& Mykytyn, 2008), and adenylyl cyclases (Kwon, Temiyasathit, Tummala, Quah, \& Jacobs, 2010; Wang, Phan, \& Storm, 2011). However, whether and how these proteins are involved in mechanosensation is largely unknown.

\section{IDENTIFICATION OF PRIMARY CILIUM}

\subsection{Cellular characterizations}

The most important aspect for assaying the mechanosensory function of primary cilia in cultured cells is to ensure that the cells possess functional cilia (Nauli et al., 2003). The first approach to promote the development of fully functional cilia is to ensure that the cultured cells are fully differentiated. Depending on the cell types, cell differentiation can usually be achieved by using a confluent cell population and/or applying a medium with low serum concentration. Because cilia are resorbed before mitosis (Nauli \& Zhou, 2004), the idea of using a confluent cell population is to allow the establishment of cell-cell contact which inhibits cell division in non-malignant cells. In most cases, contact inhibition can be achieved by culturing cells in low serum medium ( $2 \%$ or less) for additional 2-4 days (Nauli et al., 2003). Because ciliation initiates when the cells exit from the cell cycle, a quick way to promote cilium formation in kidney epithelial cell from inner medullary collecting duct is to seed cells overnight at high density in normal serum, followed by a reduction of serum to $0.5 \%$ for $48 \mathrm{~h}$ to promote ciliation. A low serum medium is always better than medium without serum to prevent-starvation-induced cell death. For a review on regulation of cilium length, see Avasthi and Marshall (2012). The protocol to promote ciliation is below.

The second approach to obtain fully functional cilia is to ensure that the fully differentiated cells possess an optimal length of cilium. An optimal length of cilium is defined as a ciliary extension which would respond to the smallest amount of fluid-shear stress. Differentiated cells do not necessarily have developed appropriate length of cilia. Certain types of cells may require additional culture time to extend their cilia, once differentiated. The best way to 
identify the optimal length of cilia is by studying the association between the cilium length and function (Nauli et al., 2008). In general, the longer the cilia, the more sensitive they are to being bent and activated by fluid-shear stress (Abdul-Majeed, Moloney, \& Nauli, 2012; Abdul-Majeed \& Nauli, 2011b). However, long cilia are less stable and can fall off easily, resulting in cells without cilia. The methods for staining cilia and measuring cilium length are described in Section 2.2.

\subsection{Ciliary polycystins}

The length of primary cilia is not a sole indicator for fully functional cilia. The presence of cilium structure must also be supported by the presence of functional sensory proteins, including polycystin-1 and -2 (Fig. 1.1B-D). The length of primary cilia can be determined by immunostaining of cultured cells. We often culture the cells on a glass coverslip for flow experiments. Preparation of glass coverslips for cell culture

1. Dilute rat type I collagen (BD Biosciences, cat\# 354236) to $50 \mu \mathrm{g} / \mathrm{mL}$ using $0.02 \mathrm{~N}$ acetic acid.

a Note that collagen is insoluble at neutral $\mathrm{pH}$.

2. Dip a glass coverslip into this collagen-containing solution for a minimum of $5 \mathrm{~s}$.

3. Place one cover slip in each well of a six-well plate.

4. Incubate coverslips at room temperature for $1 \mathrm{~h}$.

5. Add $2 \mathrm{ml}$ of phosphate-buffered saline (PBS) to the well.

6. Vigorously rinse to remove excess collagen or acid and aspirate PBS carefully.

7. Sterilize the six-well plate under UV light for at least $20 \mathrm{~min}$.

8. Plate is ready for use or it can be stored at $4{ }^{\circ} \mathrm{C}$ for up to 1 week under sterile conditions.

\section{Cell culture}

1. Add an appropriate amount of cells to $2 \mathrm{~mL}$ of culture media containing proper growth supplements or serum to the prepared six-well plates.

b Note that the higher the cell number, the faster the cells will reach confluence. Ideally, cells should be seeded at high density to reach 70 90\% confluence after overnight culture.

2. Once $95-98 \%$ confluence is reached, withdraw serum for $2-4$ days prior to flow experiments.

c Note that it is a good idea to start with reducing serum to $1 \%$. If there are too many dead cells, serum can be titrated up to $5 \%$ to prevent cell death. If cells fail to differentiate, serum can be titrated down to $0.5-$ $2 \%$. Alternatively, an additional 2 days of differentiation time can be tested. 


\section{Immunostaining for cilia and polycystins}

1. Fix cells with $4 \%$ PFA and $3 \%$ sucrose in PBS buffer for 10 min at room temperature.

d Note that the fixing solution works best when prepared fresh.

2. Wash cells with PBS buffer containing $1 \%$ BSA twice.

3. Permeabilize cells with $1 \%$ Triton-X and $1 \%$ BSA in PBS buffer for 10 min at room temperature.

4. Wash cells twice with PBS buffer containing $1 \%$ BSA.

5. Incubate cells with acetylated a-tubulin antibody, $1: 10,000$ dilution in PBS buffer for $1 \mathrm{~h}$ at room temperature, followed by washing with PBS buffer containing $1 \%$ BSA.

6. For colabeling of polycystins and cilia marker, incubate cells from Step 4 with acetylated a-tubulin antibody and polycystin-1 or polycystin-2 antibody together in order to colabel the polycystins with acetylated a-tubulin as a ciliary marker.

e Note that the ciliary localization of polycystin-1 and -2 are best immunolabeled with p96521 and p96525, respectively (Nauli et al., 2003). Incubation for $24 \mathrm{~h}$ at $4{ }^{\circ} \mathrm{C}$ is preferred to decrease nonspecific binding at dilution 1:500. Alternatively, a dilution of 1:250 can be used at room temperature for an hour. Depending on the specificity of the primary antibody, the cells can be washed with PBS (with or without $1 \%$ Triton-X). Triton- $X$ can further reduce nonspecific signals. If Triton- $X$ is used, the specimens cannot be dried out during aspiration. Any solution that contains a detergent can actually generate more background if specimens are dried during the experimental process.

7. Incubate cells with fluorophore-labeled secondary antibody against the specific species of the primary antibody used in the staining, 1:500 dilution in PBS buffer containing $1 \%$ BSA for $1 \mathrm{~h}$ at room temperature. The commonly used fluorophore conjugates are Alexa fluor 405, 488, 555, 594, and 647. Usually Alexa fluor 488 is referred to as green channel, 555 as orange, 594 as red, and 647 as far red.

8. Mount the coverslip onto a microscope slide with antifade mounting media with or without DAPI from Invitrogen. It is helpful to gentally slide the coverslip to push the cilia down and align them.

9. Leave slides in a dark place overnight to allow the mounting media to dry and then seal with nail polish and store in a dark cold place.

10. Slides can then be viewed using a fluorescence microscope equipped with the appropriate filters to match the fluorophore conjugated to the secondary antibody.

\section{Measurements of cilia length}

1. Acetylated-a-tubulin (Sigma clone 6-11B-1; 1:10,000 dilution) is commonly used as a marker for cilia length measurement. 
2. The length of primary cilia can be measured using images taken with a fluorescence microscope (inverted Nikon Ti-U or equivalent microscope) and analyzed with Metamorph 7.0 or NIS-Elements software. All image analyses are usually performed by capturing series of $Z$-stack and compiled for a more accurate measurement.

\section{MECHANOSENSORY CILIA}

\subsection{Experimental settings}

There are at least three different ways to study mechanosensory function of cilia. The first way is to directly bend one primary cilium using a micropipette (Praetorius \& Spring, 2001, 2003). While this technique is the most direct way to study mechanical function of a cilium, this is a very time-consuming method that uses a negative pressure on a single cell at a time (Fig. 1.2A). The second way is to use nanomagnetic beads precoated with ciliary-surface antibody. This technique depends greatly on the specificity of the antibody, which involves application of a magnetic field around the cell population (Fig. 1.2B). The third way to study mechanosensory function of cilia is by applying fluid-shear stress across the apical membrane of a cell population (Fig. 1.2C). This technique is probably the most physiologically relevant and has been widely utilized to study mechanociliary function (Masyuk et al., 2006; Nauli et al., 2003, 2006; Xu et al., 2007, 2009). The set up for application of fluid flow shear stress involves optimizing the perfusion, microscope, and computer systems (Fig. 1.3). Experimental setups include the following steps.

1. Briefly rinse differentiated cells with PBS containing calcium or Dulbecco's PBS (pH 7.0).

2. For calcium readout (Section 3.2), incubate cells with $\sim 10 \mu M$ Fura-2AM (Fura-2acetoxymethyl ester).

a. Fura-2AM (Teflabs, Inc., cat\# 0103) is freshly prepared to avoid fluorescence quenching, to maintain optimal loading, and to obtain good signal-to-noise ratio.

b. Prepare $1 \mathrm{~m} M$ solution of Fura-2AM by adding $50 \mu \mathrm{L}$ of high-quality anhydrous dimethyl sulfoxide (DMSO) to $50 \mu \mathrm{g}$ Fura-2AM.

c. Mix and vortex the solution for at least 5 min to ensure that Fura-2AM is homogenously dissolved in DMSO.

d. Briefly centrifuge the Fura-2AM-containing vial to avoid the use of any undissolved Fura-2AM.

3. For nitric oxide (NO) readout (Section 3.3), incubate cells with $\sim 20 \mu M$ DAF-FM (4-amino-5-methylamino-2', $7^{\prime}$-difluorofluorescein diacetate).

a. DAF-FM (Invitrogen, Inc., cat\# D-23844) is freshly prepared to avoid fluorescence quenching, to maintain optimal loading, and to obtain good signal-to-noise ratio.

b. Prepare $5 \mathrm{~m} M$ solution of DAF-FM by adding $20 \mu \mathrm{L}$ of high-quality anhydrous DMSO to $50 \mu \mathrm{g}$ of DAF-FM. 
c. Mix and vortex the solution for at least 5 min to ensure that the DAF-FM is homogenously dissolved in the DMSO.

d. Briefly centrifuge the DAF-FM-containing vial to avoid the use of any undissolved DAF-FM.

4. Discard undissolved dye by carefully pipetting $\sim 48 \mu \mathrm{L}$ of Fura-2AM or $\sim 18 \mu \mathrm{L}$ of DAF-FM solution and transfer the solution to the $5 \mathrm{~mL}$ "incubation solution." Note that the undissolved dye can be hard to wash away from the cells, which will generate unevenness in fluorescence signals or scattered bright fluorescent spots.

5. Optional: Add $0.05 \%$ of nonionic detergent Pluronic to the solution as needed.

a. Pluronic may help improve dye loading and reduce dye compartmentalization. It is most commonly used in primary cultured cells. Note that the use of Pluronic that is not rinsed or calibrated may result in fewer responsive cells.

b. Pluronic is known to enhance dye loading into the cytosolic compartment by facilitating ester solubilization. However, excessive loading of Fura-2AM from Pluronic can cause cellular acidification as a result of the formaldehyde release from acetoxymethyl ester (AM) hydrolysis (Nauli, Zhang, \& Pearce, 2001; Nauli et al., 2011; Van der Zee, Mason, \& Eling, 1989).

c. Cellular acidification is considered negligible if the maximum cytosolic calcium changes are not altered with Pluornic.

d. The use of probenecid helps maintain the Fura dye inside the cells during the experimental period.

6. Depending on the length of the experiment, the "incubation solution" can simply be the Krebs buffer, modified Dulbecco's modified Eagle medium, or HEPES buffer.

a. Krebs buffer solution is used only when the entire chamber system is supported by continuous bubbles of $95 \% \mathrm{O}_{2}-5 \% \mathrm{CO}_{2}$ (Nauli, Williams, Akopov, Zhang, \& Pearce, 2001). This solution is usually perceived as the most physiologically representative buffer, although it is usually difficult to have homogenous aeration in most of flow systems. A Krebs buffer solution contains (in $\mathrm{mM}$ ): $122 \mathrm{NaCl}, 25.6 \mathrm{NaHCO}_{3}, 5.56$ dextrose, 5.17 $\mathrm{KCl}, 2.49 \mathrm{MgSO}_{4}, 1.60 \mathrm{CaCl}_{2}, 0.114$ ascorbic acid, and $0.027 \mathrm{EGTA}$, and is continuously bubbled with $95 \% \mathrm{O}_{2}-5 \% \mathrm{CO}_{2}$ to maintain a $\mathrm{pH}$ of 7.2.

b. A modified Dulbecco's modified Eagle medium is used to avoid interactions between $\mathrm{pH}$ indicator phenol red with Fura-2 fluorescence signal (Nauli et al., 2003). It is also modified to avoid limitation with aeration of $95 \% \mathrm{O}_{2}-5 \% \mathrm{CO}_{2}$. The modified medium contains (in $\mathrm{mM}$ ): $1.26 \mathrm{CaCl}_{2}, 0.81 \mathrm{MgSO}_{4}, 5.37 \mathrm{KCl}, 0.44 \mathrm{KH}_{2} \mathrm{PO}_{4}, 137 \mathrm{NaCl}, 0.34$ $\mathrm{Na}_{2} \mathrm{HPO}_{4}, 5.55 \mathrm{D}$-glucose, 2.0 L-glutamine, 1.0 sodium pyruvate, $1 \%$ bovine serum albumin, and 20.0 HEPES at pH 7.2. 
c. HEPES buffer solution has the simplest composition, and it is usually used for experiments that are not longer than $30 \mathrm{~min}$ (AbouAlaiwi et al., 2009). For shock-sensitive cells, this buffer solution may not be optimal. The solution contains (in $\mathrm{m} M$ ): $138 \mathrm{NaCl}, 2 \mathrm{CaCl}_{2}, 1 \mathrm{MgCl}_{2}, 5 \mathrm{KCl}, 10 \mathrm{D}$ glucose, 10.0 HEPES at $\mathrm{pH}$ 7.4.

7. Incubate cells with a solution containing Fura-2AM and/or DAF-FM for $30 \mathrm{~min}$.

a. If simultaneous loading of Fura-2AM and DAF-FM is desired, each dye should be tried individually to obtain its optimal loading condition, before loading both dyes.

b. Incubation with the fluorophore dye can be achieved at $38^{\circ} \mathrm{C}$ for human cells or $33{ }^{\circ} \mathrm{C}$ for mouse cells. In some cases, loading at $39^{\circ} \mathrm{C}$ could be optimal to control cell differentiation, especially when the cells are immortalized with Simian Virus-40 (Loghman-Adham, Nauli, Soto, Kariuki, \& Zhou, 2003).

8. Once loaded, gently transfer the cells to a perfusion chamber and equilibrate for at least $15 \mathrm{~min}$ before challenged with fluid-shear stress.

a. There are many commercially available perfusion chambers. One can also use a custom-made chamber. Regardless of which chamber is used, it is imperative to confirm that a laminar fluid flow can be obtained. It is also important to note that some chambers have a much lower range of laminar flow, in which a high flow rate would generate turbulence flow which would form pressure inside the chamber.

b. It is important to avoid pressure accumulation in the chamber. This can be easily tested by growing the cells on a No. 0 coverslip. Since a No. 0 coverslip is thin enough to be easily bent by pressure, under a $40 x$ objective, any turbulence or pressure generated from the flow would change the focus of the cells.

c. The shape and dimension of the chamber needs to be properly determined because they are factored into the calculated shear stress.

d. In most cases, the thickness and width of the perfusion chamber will be used in shear stress calculation.

9. Equilibrate cells for $\sim 30$ min before being challenged with fluid flow.

a. Each cell type has a specific ciliary length, which reflects their optimal fluid-shear stress.

b. Test for the optimal shear stress by applying a range of shear stress from 0.1 to $50 \mathrm{dyne} / \mathrm{cm}^{2}$. The optimal shear stress value is defined as the largest change in cytosolic calcium indicated by the ratiometric Fura- 2 signal (Section 3.2).

10. Depending on the shape of the chamber, shear stress can be calculated using the following formula. 
a. Cylindrical shape: $\tau_{\mathrm{w}}=\frac{4 Q \eta}{\pi r^{3}}$

b. Rectangular prism: $\tau_{\mathrm{w}}=\frac{6 Q \eta}{a^{2} b}$

$\tau_{\mathrm{w}}=$ wall shear stress in dyne $/ \mathrm{cm}^{2}$

$Q=$ volumetric flow rate in $\mathrm{mL} / \mathrm{s}$

$\eta=$ apparent fluid viscosity in dyne $\mathrm{s} / \mathrm{cm}^{2}$

$\pi=$ pi with a constant value of 3.1428

$r=$ radius of cylinder in $\mathrm{cm}$

$a=$ height of the chamber or thickness of gasket in $\mathrm{cm}$

$b=$ width of the chamber or gasket in $\mathrm{cm}$.

c. At $33-39^{\circ} \mathrm{C}$, when Krebs buffer, modified Dulbecco's modified Eagle medium, or HEPES buffer is used as "incubation solution" for perfusion, the calculated viscosity is approximately 0.0076 dyne $\mathrm{s} / \mathrm{cm}^{2}$.

d. Flow-induced cilium activation is accomplished by a step change in fluid flow rate from a static condition to the designated shear stress. Because the dimension of the perfusion chamber remains the same, only the volumetric flow rate is adjusted by controlling the speed of a continuous or pulsate pump to provide a desired shear stress value.

\subsection{Calcium readout}

Because calcium is the most universal second messenger, it is not surprising that intracellular calcium has been widely used as readout for cilium function. Calcium readout has been used to study mechanosensory cilia in renal epithelia (Nauli et al., 2003, 2006; Xu et al., 2007, 2009), cholangiocyte epithelia (Masyuk et al., 2006), vascular endothelia (AbouAlaiwi et al., 2009; Nauli et al., 2008), osteoblast (Qiu et al., 2012; Xiao, Zhang, Magenheimer, Luo, \& Quarles, 2008), osteocyte (Qiu et al., 2012; Xiao et al., 2008), embryonic neurula nodal cells (McGrath et al., 2003), and many others (Fig. 1.4).

1. Calcium dye selections

a. Although many different calcium-sensitive fluorescence dyes are commercially available, there is no specific preference for use in examining cytosolic calcium. However, it is recommended that ratiometric dye such as Fura-2AM is used for confirmation purposes (Fig. 1.4).

Fura-2AM is a ratiometric dye. It can be excited by two wavelengths, 340 $\mathrm{nm}$ for calcium bound and $380 \mathrm{~nm}$ for unbound. Irrespective of the excitation wavelength, the dye will emit at $510 \mathrm{~nm}$ wavelength. The ratio of 340/380 is usually calculated for normalizing unequal loading of the dye into the cells.

b. Fluid flow over the top of cells could change the intensity of background fluorescence. If a nonratiometric calcium fluorophore is used, it is always recommended to confirm the results with Fura-2AM. This is especially 
necessary in well-differentiated confluent cells, in which changes in cellfree background intensity are most likely not achievable.

2. Calcium dye toxicity

a. Fura-2AM is membrane permeable due to its AM group. The AM group can be hydrolyzed easily by nonspecific membrane esterase (Nauli, Zhang, et al., 2001; Van der Zee et al., 1989).

b. Acidification of the cells as a result of formaldehyde release from the AM hydrolysis is usually negligible, but it can be a problem in cells overloaded with Fura-2.

c. Optimal loading of calcium fluorophores can be easily determined by challenging the cells with ATP. The time course and peak magnitude of calcium signals in response to ATP should be sufficient to indicate the cell viability.

3. Calcium dye signals

a. To distinguish the Fura-2 calcium signal from autofluorescence or movement artifacts, the intensities emitted at 340 and $380 \mathrm{~nm}$ should always be monitored separately in addition to measurements of their ratio.

b. Only preparations in which 340 and 380 signals change as mirror images (inversely) of one another should be used. For example, a true increase in cytosolic calcium would result in an increase in 340 signal but a decrease in 380 signal intensities.

c. Paired Fura-2 images should be captured at a minimum of every $5 \mathrm{~s}$ at excitation wavelengths of 340 and $380 \mathrm{~nm}$.

d. The optimal shear stress value is defined as the largest changes in cytosolic calcium indicated by the ratiometric Fura-2 dye (340:380).

4. Quantification of free intracellular calcium

a. After completion of the experiment, the minimum fluorescence should be obtained by incubation of the preparations in calcium-free perfusion solution containing $2 \mathrm{~m} M$ EGTA and $10 \mu M$ ionomycin at $\mathrm{pH} 8.6$ to optimize the ionomycin effect.

b. After the minimum signal ratio is determined, the same cell preparation is challenged with excess calcium $(10 \mathrm{mM})$ to obtain the maximum signal ratio.

c. All of the fluorescence measurements should be corrected for autofluorescence.

d. The exact free calcium values can then be calculated using formulas provided by the manufacture. If using the Fura-2AM dye from Invitrogen, the following formula will be used. $\left[\mathrm{Ca}^{2+}\right]=K_{\mathrm{d}} \times Q\left(R-R_{\min }\right) /\left(R_{\max }-R\right)$. Where $K_{\mathrm{d}}$ is the dissociation constant of the dye from the released 
calcium, $R$ is the measured ratio F340/F380, and $R_{\min }$ and $R_{\max }$ are the fluorescence ratios at minimum and maximum ion concentration. It is very important to calibrate and measure the dye $K_{\mathrm{d}}$ using the F340/F380 obtained from measuring known calcium concentrations for calibration. The $K_{\mathrm{d}}$ of the used dye for calcium imaging is very important as it determines the sensitivity of the dye and its resolution. For example, Fura-2AM has very limited sensitivity of calcium above $1 \mu M$ concentration. For this reason, different Fura-2 derivatives are available with variable $\mathrm{Kd}$ (values). The Fura-2AM calcium imaging calibration kit (cat\# F6774) from Invitrogen makes the calibration a lot easier.

\subsection{Nitric oxide readout}

NO is probably the most potent endogenous vasodilator. Vascular endothelial cells are known to readily synthesize and release $\mathrm{NO}$ in response to many stimuli, including fluidshear stress (Fig. 1.5). Not surprisingly, NO production has always been assayed to confirm blood vessel functionality (Vita, 2011). Furthermore, other cell types including renal epithelial cells have also been shown to have the ability to produce NO (Garvin, Herrera, \& Ortiz, 2011). Depending on the experimental purposes, NO measurement can be done with NO-specific fluorophore (DAF-FM) or nitrite-specific dye (diaminonaphthalene, DAN).

1. Measuring intracellular NO with DAF-FM (AbouAlaiwi et al., 2009; Nauli et al., 2008)

a. The advantages of this technique are that (a) it permits live observation and live-imaging analysis of NO biosynthesis, (b) it can be simultaneously used with Fura-2AM to understand the biochemical interactions between calcium signaling and NO biosynthesis, and (c) it allows high-resolution temporal and spatial image acquisitions.

b. The disadvantage is that DAF-FM provides only relative levels of intracellular NO. The baseline value of the corrected fluorescence (after background subtraction) is usually defined as $100 \%$. All subsequent fluorescence values measured in the same preparation are normalized relative to this value. Coupled with DAN, however, both techniques could be extremely powerful to analyze NO production and release.

c. Due to the high diffusion coefficient of NO gas, intracellular NO should be measured at a minimum of every $5 \mathrm{~s}$ at the excitation and emission wavelengths of 495 and $515 \mathrm{~nm}$, respectively.

2. Measuring extracellular NO release with DAN

a. DAN is an $\mathrm{NO}_{2}{ }^{-}$-specific dye. Thus, $\mathrm{NO}_{2}{ }^{-}$is assayed from the collected perfusate media.

b. Because NO gas escapes easily from the cells to the media, extracellular release of $\mathrm{NO}$ can be measured indirectly with nitrate/nitritefluoremetric assay kit (Cayman Chemical, Corp.). NO gas is converted easily to nitrite $\left(\mathrm{NO}_{2}^{-}\right)$and nitrate $\left(\mathrm{NO}_{3}{ }^{-}\right)$. Because the relative proportion of this 
conversion is too variable to predict with certainty, all of the $\mathrm{NO}_{3}{ }^{-}$in the media is reduced to $\mathrm{NO}_{2}{ }^{-}$prior to the extracellular $\mathrm{NO}$ measurement. Therefore, this extracellular $\mathrm{NO}$ assay provides a measurement of total $\mathrm{NO}_{2}{ }^{-}$and $\mathrm{NO}_{3}{ }^{-}$in the media through a two-step process.

c. The first step involves conversion of $\mathrm{NO}_{3}{ }^{-}$to $\mathrm{NO}_{2}{ }^{-}$by a nitrate reductase enzyme. The second step involves the addition of DAN to specifically detect $\mathrm{NO}_{2}{ }^{-}$. DAN and $\mathrm{NO}_{2}{ }^{-}$react easily, resulting in highly fluorescence chemical designated as naphthotriazole (NAT). Further alkaline treatment of NAT would enhance its fluorescence characteristics with excitation of $360 \mathrm{~nm}$ and emission of $430 \mathrm{~nm}$.

d. For each 96-well plate measurement, a replicated standard curve with a known $\mathrm{NO}_{3}{ }^{-}$concentration is generated by first converting it to $\mathrm{NO}_{2}{ }^{-}$. The NAT fluorescence is then analyzed with multi-detection microplate reader at the optimal excitation and emission wavelengths of 360 and 430 $\mathrm{nm}$, respectively.

\subsection{Protein readout}

Fluid-shear stress has been shown to induce various gene expressions and protein modifications (AbouAlaiwi, Lo, \& Nauli, 2009; Nollert, Panaro, \& McIntire, 1992; Ten Dijke, Egorova, Goumans, Poelmann, \& Hierck, 2012). Whether or not these changes depend on cilium function, however, remains unknown. What has been confirmed by independent laboratories is that fluid-shear-induced cilium activation will result in polycystin-1 cleavage (Chauvet et al., 2004; Low et al., 2006; Nauli et al., 2008). It is thus justified to include analysis of polycystin-1 as another potential readout for cilium function (Fig. 1.6). One quick and relative easy way to determine the cleavage of polycystin-1 is to perform immunoprecipitation-Western analysis using antibody against the C-terminal of polycystin-1 (anti-polycystin-1 at 1:5 dilution; P-15 from Santa Cruz Biotechnology, Inc.). This is a relatively simple biochemical assay for mechanosensory function of primary cilia.

\section{SUMMARY}

Substantial evidence exists confirming the role of primary cilium as a mechanosensory organelle in various organ systems. Although both structure and function of primary cilium are required for its sensory functions, analysis of cilium functionevenin cells with a known structural defect isrecommended, as cilium length and function may not be well correlated (Abdul-Majeed et al., 2012; Abdul-Majeed \& Nauli, 2011b). Calcium is the most universal second messenger, which has been associated with mechanisms involved in cilia-related cystic phenotypes (Abdul-Majeed \& Nauli, 2011a; Nauli \& Zhou, 2004). NO biosynthesis and protein modification are also reliable readouts of mechanosensory function of primarycilia. Other readouts of cilium function are being explored and developed. Therefore, more interesting research is yet to be done to complement the existing tools in studying the physiological and molecular aspects of nonmotile primary cilia. 


\section{Acknowledgments}

The authors thank Charisse Montgomery for her editorial review of the manuscript. This work was supported by grants DK080640 to S. M. N., and RO1DK51050 and RO1DK53357 to J. Z.

\section{References}

Abdul-Majeed S, Moloney BC, Nauli SM. Mechanisms regulating cilia growth and cilia function in endothelial cells. Cellular and Molecular Life Sciences. 2012; 69(1):165-173. [PubMed: 21671118]

Abdul-Majeed S, Nauli SM. Calcium-mediated mechanisms of cystic expansion. Biochimica et Biophysica Acta. 2011a; 1812(10):1281-1290. [PubMed: 20932898]

Abdul-Majeed S, Nauli SM. Dopamine receptor type 5 in the primary cilia has dual chemo- and mechano-sensory roles. Hypertension. 2011b; 58(2):325-331. [PubMed: 21709211]

Abdul-Majeed S, Nauli SM. Polycystic diseases in visceral organs. Obstetrics and Gynecology International. 2011c; 2011:609370. [PubMed: 22242024]

AbouAlaiwi WA, Lo ST, Nauli SM. Primary cilia: Highly sophisticated biological sensors. Sensors (Basel). 2009; 9(9):7003-7020. [PubMed: 22423203]

AbouAlaiwi WA, Ratnam S, Booth RL, Shah JV, Nauli SM. Endo-thelial cells from humans and mice with polycystic kidney disease are characterized by polyploidy and chromosome segregation defects through survivin down-regulation. Human Molecular Genetics. 2011; 20(2):354-367. [PubMed: 21041232]

AbouAlaiwi WA, Takahashi M, Mell BR, Jones TJ, Ratnam S, Kolb RJ, et al. Ciliary polycystin-2 is a mechanosensitive calcium channel involved in nitric oxide signaling cascades. Circulation Research. 2009; 104(7):860-869. [PubMed: 19265036]

Avasthi P, Marshall WF. Stages of ciliogenesis and regulation of ciliary length. Differentiation. 2012; 83(2):S30-S42. [PubMed: 22178116]

Berbari NF, Johnson AD, Lewis JS, Ask with CC, Mykytyn K. Identification of ciliary localization sequences within the third intracellular loop of $\mathrm{G}$ protein-coupled receptors. Molecular Biology of the Cell. 2008; 19(4):1540-1547. [PubMed: 18256283]

Boehlke C, Kotsis F, Patel V, Braeg S, Voelker H, Bredt S, et al. Primary cilia regulate mTORC1 activity and cell size through Lkb1. Nature Cell Biology. 2010; 12(11):1115-1122.

Cano DA, Murcia NS, Pazour GJ, Hebrok M. Orpk mouse model of polycystic kidney disease reveals essential role of primary cilia in pancreatic tissue organization. Development. 2004; 131(14): 3457-3467. [PubMed: 15226261]

Cano DA, Sekine S, Hebrok M. Primary cilia deletion in pancreatic epithelial cells results in cyst formation and pancreatitis. Gastroenterology. 2006; 131(6):1856-1869. [PubMed: 17123526]

Chauvet V, Tian X, Husson H, Grimm DH, Wang T, Hiesberger T, et al. Mechanical stimuli induce cleavage and nuclear translocation of the polycystin-1 C terminus. The Journal of Clinical Investigation. 2004; 114(10):1433-1443. [PubMed: 15545994]

Ezratty EJ, Stokes N, Chai S, Shah AS, Williams SE, Fuchs E. A role for the primary cilium in Notch signaling and epidermal differentiation during skin development. Cell. 2011; 145(7):1129-1141. [PubMed: 21703454]

Fuchs JL, Schwark HD. Neuronal primary cilia: A review. Cell Biology International. 2004; 28(2): 111-118. [PubMed: 14984756]

Garvin JL, Herrera M, Ortiz PA. Regulation of renal $\mathrm{NaCl}$ transport by nitric oxide, endothelin, and ATP: Clinical implications. Annual Review of Physiology. 2011; 73:359-376.

Handel M, Schulz S, Stanarius A, Schreff M, Erdtmann-Vourliotis M, Schmidt H, et al. Selective targeting of somatostatin receptor 3 to neuronal cilia. Neuroscience. 1999; 89(3):909-926. [PubMed: 10199624]

Hou B, Kolpakova-Hart E, Fukai N, Wu K, Olsen BR. The polycystic kidney disease 1 (Pkd1) gene is required for the responses of osteochondroprogenitor cells to midpalatal suture expansion in mice. Bone. 2009; 44(6):1121-1133. [PubMed: 19264154]

Ingham PW, Nakano Y, Seger C. Mechanisms and functions of Hedgehog signalling across the metazoa. Nat Rev Genet. 2011; 12(6):393-406. [PubMed: 21502959] 
Kwon RY, Temiyasathit S, Tummala P, Quah CC, Jacobs CR. Primary cilium-dependent mechanosensing is mediated by adenylyl cyclase 6 and cyclic AMP in bone cells. The FASEB Journal. 2010; 24(8):2859-2868.

Loghman-Adham M, Nauli SM, Soto CE, Kariuki B, Zhou J. Immortalized epithelial cells from human autosomal dominant polycystic kidney cysts. American Journal of Physiology. Renal Physiology. 2003; 285(3):F397-F412. [PubMed: 12734101]

Low SH, Vasanth S, Larson CH, Mukherjee S, Sharma N, Kinter MT, et al. Polycystin-1, STAT6, and P100 function in a pathway that transduces ciliary mechanosensation and is activated in polycystic kidney disease. Developmental Cell. 2006; 10(1):57-69. [PubMed: 16399078]

Lu W, Shen X, Pavlova A, Lakkis M, Ward CJ, Pritchard L, et al. Comparison of Pkd1-targeted mutants reveals that loss of polycystin-1 causes cystogenesis and bone defects. Human Molecular Genetics. 2001; 10(21):2385-2396. [PubMed: 11689485]

Luyten A, Su X, Gondela S, Chen Y, Rompani S, Takakura A, et al. Aberrant regulation of planar cell polarity in polycystic kidney disease. Journal of the American Society of Nephrology. 2010; 21(9): 1521-1532. [PubMed: 20705705]

Magloire H, Couble ML, Romeas A, Bleicher F. Odontoblast primary cilia: Facts and hypotheses. Cell Biology International. 2004; 28(2):93-99. [PubMed: 14984754]

Masyuk AI, Masyuk TV, Splinter PL, Huang BQ, Stroope AJ, LaRusso NF. Cholangiocyte cilia detect changes in luminal fluid flow and transmit them into intracellular Ca2+ and cAMP signaling. Gastroenterology. 2006; 131(3):911-920. [PubMed: 16952559]

McGrath J, Somlo S, Makova S, Tian X, Brueckner M. Two populations of node monocilia initiate left-right asymmetry in the mouse. Cell. 2003; 114(1):61-73. [PubMed: 12859898]

McGlashan SR, Jensen CG, Poole CA. Localization of extracellular matrix receptors on the chondrocyte primary cilium. J Histochem Cytochem. 2006; 54(9):1005-1014. [PubMed: 16651393]

Nauli SM, Alenghat FJ, Luo Y, Williams E, Vassilev P, Li X, et al. Poly-cystins 1 and 2 mediate mechanosensation in the primary cilium of kidney cells. Nature Genetics. 2003; 33(2):129-137. [PubMed: 12514735]

Nauli, SM.; Haymour, HS.; AbouAlaiwi, WA.; Lo, ST.; Nauli, AM. Primary cilia are mechanosensory organelles in vestibular tissues. In: Kamkin, Andre; Kiseleva, Irina, editors. Mechanosensitivity and mechanotransduction. Vol. chapter 14. New York: Springer; 2011.

Nauli SM, Kawanabe Y, Kaminski JJ, Pearce WJ, Ingber DE, Zhou J. Endothelial cilia are fluid shear sensors that regulate calcium signaling and nitric oxide production through polycystin-1. Circulation. 2008; 117(9):1161-1171. [PubMed: 18285569]

Nauli SM, Rossetti S, Kolb RJ, Alenghat FJ, Consugar MB, Harris PC, et al. Loss of polycystin-1 in human cyst-lining epithelia leads to ciliary dysfunction. Journal of the American Society of Nephrology. 2006; 17(4):1015-1025. [PubMed: 16565258]

Nauli SM, Williams JM, Akopov SE, Zhang L, Pearce WJ. Developmental changes in ryanodine- and IP(3)-sensitive $\mathrm{Ca}(2+)$ pools in ovine basilar artery. American Journal of Physiology. Cell Physiology. 2001; 281(6):C1785-C1796. [PubMed: 11698236]

Nauli SM, Zhang L, Pearce WJ. Maturation depresses cGMP-mediated decreases in [Ca2+]i and Ca2+ sensitivity in ovine cranial arteries. American Journal of Physiology. Heart and Circulatory Physiology. 2001; 280(3):H1019-H1028. [PubMed: 11179043]

Nauli SM, Zhou J. Polycystins and mechanosensation in renal and nodal cilia. Bioessays. 2004; 26(8): 844-856. [PubMed: 15273987]

Nollert MU, Panaro NJ, McIntire LV. Regulation of genetic expression in shear stress-stimulated endothelial cells. Annals of the New York Academy of Sciences. 1992; 665:94-104. [PubMed: 1416623]

Praetorius HA, Spring KR. Bending the MDCK cell primary cilium increases intracellular calcium. The Journal of Membrane Biology. 2001; 184(1):71-79. [PubMed: 11687880]

Praetorius HA, Spring KR. Removal of the MDCK cell primary cilium abolishes flow sensing. The Journal of Membrane Biology. 2003; 191(1):69-76. [PubMed: 12532278] 
Praetorius HA, Praetorius J, Nielsen S, Frokiaer J, Spring KR. Beta1-integrins in the primary cilium of MDCK cells potentiate fibronectin-induced Ca2+ signaling. Am J Physiol Renal Physiol. 2004; 287(5):F969-978. [PubMed: 15226154]

Qiu N, Xiao Z, Cao L, Buechel MM, David V, Roan E, et al. Disruption of Kif3a in osteoblasts results in defective bone formation and osteopenia. Journal of Cell Science. 2012; 125(8):1945-1957. [PubMed: 22357948]

Resnick A. Chronic fluid flow is an environmental modifier of renal epithelial function. PLoS One. 2011; 6(10):e27058. [PubMed: 22046444]

Schneider L, Cammer M, Lehman J, Nielsen SK, Guerra CF, Veland IR, et al. Directional cell migration and chemotaxis in wound healing response to PDGF-AA are coordinated by the primary cilium in fibroblasts. Cellular Physiology and Biochemistry. 2010; 25(2-3):279-292. [PubMed: 20110689]

Schneider L, Stock CM, Dieterich P, Jensen BH, Pedersen LB, Satir P, et al. The Na+/H+ exchanger NHE1 is required for directional migration stimulated via PDGFR-alpha in the primary cilium. The Journal of Cell Biology. 2009; 185(1):163-176. [PubMed: 19349585]

Ten Dijke P, Egorova AD, Goumans MJ, Poelmann RE, Hierck BP. TGF-beta signaling in endothelial-to-mesenchymal transition: The role of shear stress and primary cilia. Science Signaling. 2012; 5(212) pt2.

Thivichon-Prince B, Couble ML, Giamarchi A, Delmas P, Franco B, Romio L, et al. Primary cilia of odontoblasts: Possible role in molar morphogenesis. Journal of Dental Research. 2009; 88(10): 910-915. [PubMed: 19783798]

Van der Zee J, Mason RP, Eling TE. The oxidation of the calcium probe quin 2 and its analogs by prostaglandin H synthase. Archives of Biochemistry and Biophysics. 1989; 271(1):64-71. [PubMed: 2540717]

Vita JA. Endothelial function. Circulation. 2011; 124(25):e906-e912. [PubMed: 22184047]

Wang Z, Phan T, Storm DR. The type 3 adenylyl cyclase is required for novel object learning and extinction of contextual memory: Role of cAMP signaling in primary cilia. The Journal of Neuroscience. 2011; 31(15):5557-5561. [PubMed: 21490195]

Xiao Z, Zhang S, Magenheimer BS, Luo J, Quarles LD. Polycystin-1 regulates skeletogenesis through stimulation of the osteoblast-specific transcription factor RUNX2-II. The Journal of Biological Chemistry. 2008; 283(18):12624-12634. [PubMed: 18321855]

Xiao Z, Zhang S, Mahlios J, Zhou G, Magenheimer BS, Guo D, et al. Cilia-like structures and polycystin-1 in osteoblasts/osteocytes and associated abnormalities in skeletogenesis and Runx2 expression. The Journal of Biological Chemistry. 2006; 281(41):30884-30895. [PubMed: 16905538]

Xu C, Rossetti S, Jiang L, Harris PC, Brown-Glaberman U, Wandinger-Ness A, et al. Human ADPKD primary cyst epithelial cells with a novel, single codon deletion in the PKD1 gene exhibit defective ciliary polycystin localization and loss of flow-induced Ca2+ signaling. American Journal of Physiology. Renal Physiology. 2007; 292(3):F930-F945. [PubMed: 17090781]

Xu C, Shmukler BE, Nishimura K, Kaczmarek E, Rossetti S, Harris PC, et al. Attenuated, flowinduced ATP release contributes to absence of flow-sensitive, purinergic Cai2+ signaling in human ADPKD cyst epithelial cells. American Journal of Physiology. Renal Physiology. 2009; 296(6):F1464-F1476. [PubMed: 19244404]

Zhou J. Polycystins and primary cilia: Primers for cell cycle progression. Annual Review of Physiology. 2009; 71:83-113. 

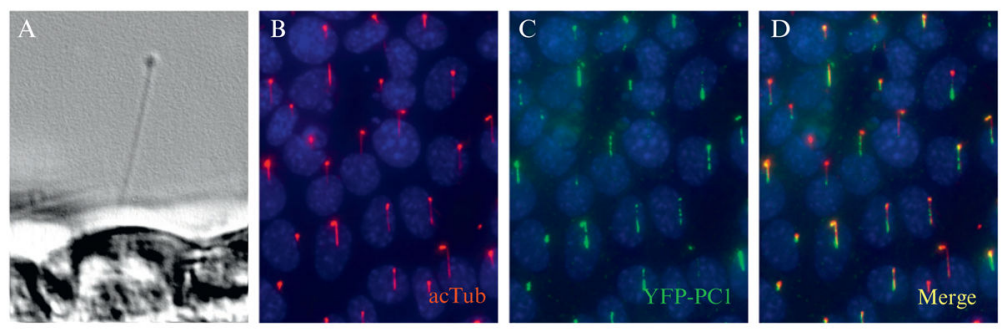

Figure 1.1.

Sensory primary cilium in endothelial and epithelial cells. A primary cilium is a sensory organelle that projects to the extracellular space from the apical membrane of a cell. (A) Phase contrast image of a primary cilium projecting from the apical surface of an endothelial cell. (B-D) Double staining of primary cilia and yellow fluorescent protein (YFP)-tagged polycystin-1 shown in a monolayer of kidney epithelial cells with an antibody against acetylated a-tubulin (red) (B) and an antibody against YFP (green) (C). A merged image of (B) and (C) is shown in (D). Nuclei are stained by $4^{\prime}, 6$-diamidino-2-phenylindole (DAPI) in blue. 

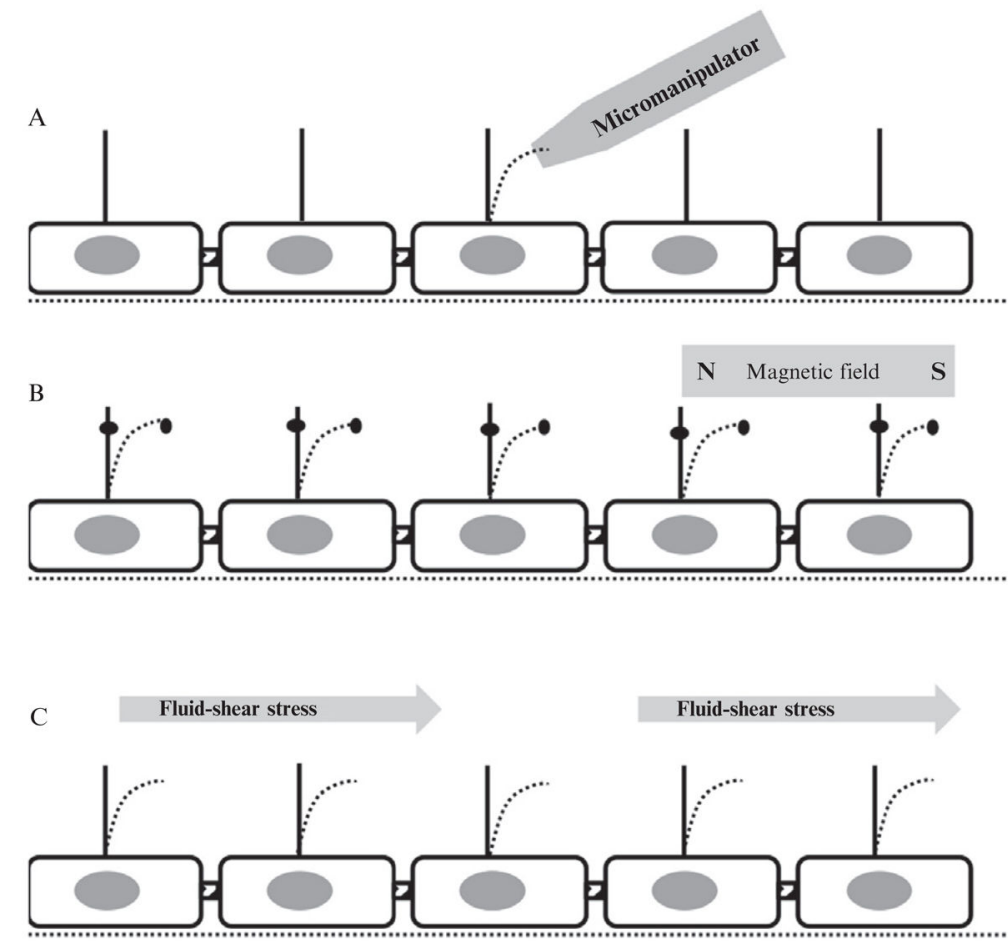

Figure 1.2.

Techniques to study mechanosensory function of cilia. There are at least three different ways to study mechanosensory function of cilia. (A) The first way is to directly bend one primary cilium by applying a negative pressure at the tip of a micropipette. (B) The second way to study sensory function of cilia is with nanomagnetic beads, precoated with ciliarysurface-specific antibody. The nano beads can be twisted or pulled by applying magnetic field around the cells. (C) The third and more physiological way to examine cilium function is to apply fluid shear on the top of the cells. This technique is the most robust and inexpensive way to analyze mechanosensory function of cilia. 
A

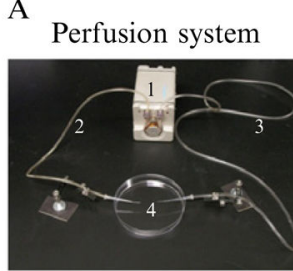

Items to be considered:

1. Multi-speed pump

2. Fluid flow (input)

3. Fluid flow (output)

4. Flow chamber

C

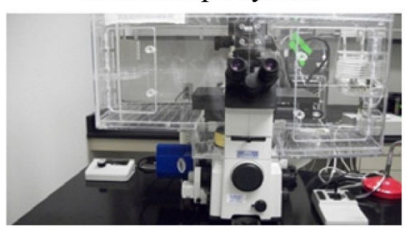

Items to be considered:

1. Speed of camera

2. Fluorescence intensity

3. Fluorescence lens and filters

4. Temperature, gas, and humidity
B

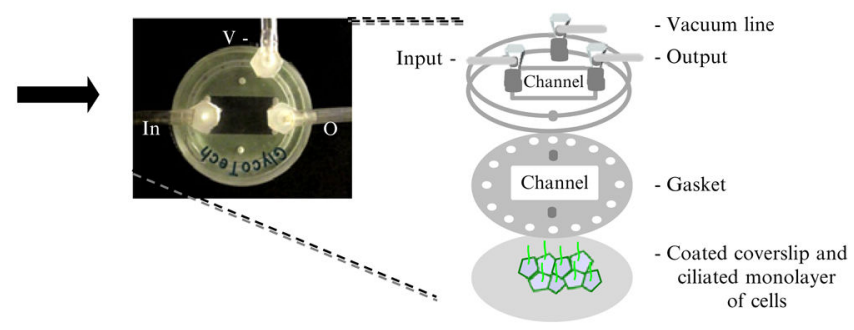

D Computer system

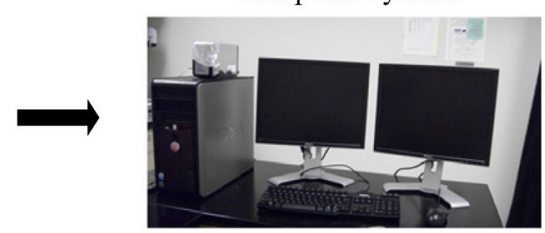

Items to be considered:

1. Computer speed

2. RAM and hard drive

3. Software for image capturing and image analysis

Figure 1.3.

Experimental setup for fluid-shear stress to study cilium function. To investigate the mechanosensory role of primary cilia with fluid-shear stress requires a setup with at least three components. (A) A perfusion system includes a reliable pump that would generate the same input and output volumes to the perfusion chamber in a "closed" perfusion system. A more reliable "open" perfusion system usually uses two pumps to control the input and output volumes. In either case, it is important to avoid pressure in the chamber to prevent bubble formation and turbulence flow. (B) A cartoon illustrating the assembly of the commonly used Glycotech perfusion chamber. (C) A microscope system that is capable to support experimental conditions and specifications. The speeds of camera and excitation/ emission wavelengths changers have to be fast enough, especially when calcium signals at $340 / 380 \mathrm{~nm}$, nitric oxide signals at $495 \mathrm{~nm}$, and phase contrast images are to be captured. These speeds can alternatively be controlled with the intensity of fluorescence or visual light. An environmental chamber is recommended for better control temperature, $\mathrm{CO}_{2} / \mathrm{O}_{2}$, and humidity and to prevent condensation on the objective lens and the perfusion chamber. (D) A computer system with up-to-date software such as NIS-elements to support experimental specifications and microscopic functions during image capturing or data analysis. 

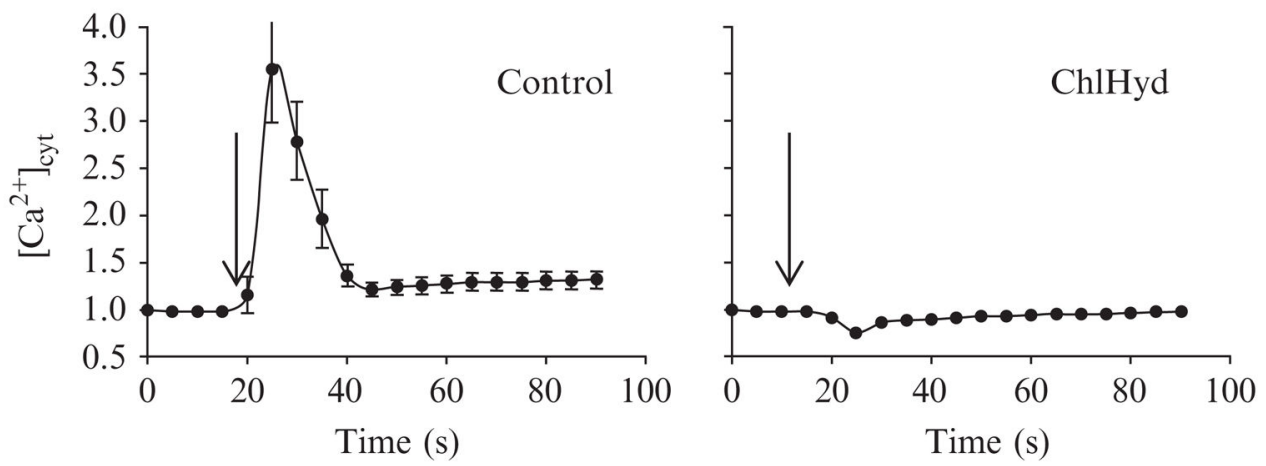

Figure 1.4.

Intracellular free calcium as a readout of ciliary function. Cytosolic free calcium $\left(\left[\mathrm{Ca}^{2+}\right]_{\text {cyt }}\right)$ in response to fluid-shear stress is measured with Fura-2. Wild-type embryonic endothelial cells treated without (control) and with chloral hydrate (ChlHyd; $4 \mathrm{mM}, 12 \mathrm{~h}$ ) are challenged with shear stress. Chloral hydrate reversibly blocks the formation of primary cilia or destroys cilia structure. Arrows indicate the step increase in fluid-shear stress. 

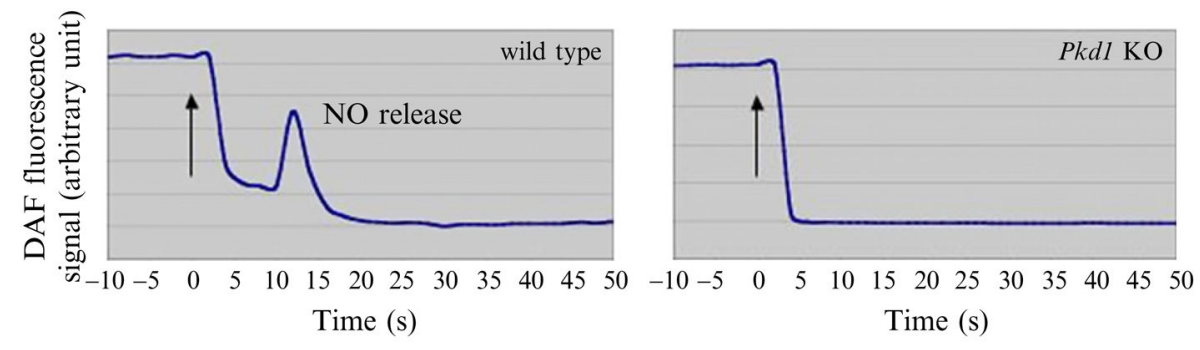

\section{Figure 1.5.}

Intracellular nitric oxide biosynthesis as a readout of ciliary function. Cytosolic nitric oxide biosynthesis $\left([\mathrm{NO}]_{\mathrm{cyt}}\right)$ in response to fluid-shear stress is measured with DAF-FM. Wildtype or $P k d l$ knockout embryonic endothelial cells are challenged with shear stress. The graphs depict original traces before background subtraction and normalization (note that the $y$-axis is unitless). Changes in autofluorescence were seen when shear stress was applied on the cells at $0 \mathrm{~s}$. Fluid flow has been known to change autofluorescence either by increasing or decreasing it. Thus, proper experimental controls such as cells with no cilium function or structure are required if ratiometric dye (like Fura-2) is not used. Arrows indicate the step increase in fluid-shear stress. 


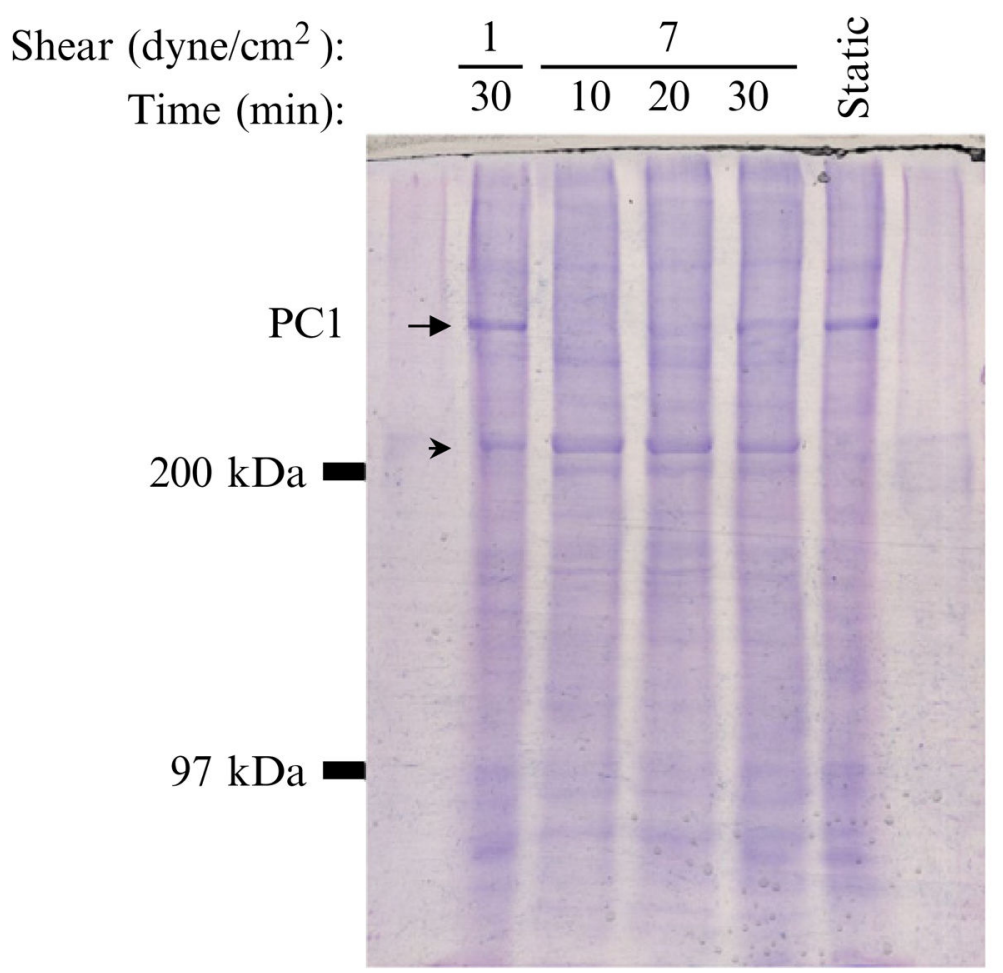

\section{Figure 1.6.}

Proteomic analysis as a readout of cilium function. Fluid-shear stress has been shown to modify various proteins, including polycystin-1 cleavage. After endothelial cells are equilibrated at 0,1 , or $7 \mathrm{dyne} / \mathrm{cm}^{2}$ for 10,20 , or $30 \mathrm{~min}$, the total proteins are collected and coimmunoprecipitated with polycystin-1 antibody (P-15, Santa Cruz Biotechnology). Only a single full-length of polycystin-1 band is observed in static control cells (arrow), while fluidshear stress induces a second lower molecular weight of polycystin-1 band (arrow head).

Note that the band intensity of full-length polycystin-1 in cells equilibrated at $7.2 \mathrm{dyne} / \mathrm{cm}^{2}$ is much weaker compared to cells of static control or $1.1 \mathrm{dyne} / \mathrm{cm}^{2}$. 